\title{
On the Strategic Choice of Union-Oligopoly Bargaining Agenda: Further Results
}

\author{
Domenico Buccella ${ }^{1}$ and Luciano Fanti ${ }^{2}$ \\ ${ }^{1}$ Department of Economics, Kozminski University, Jagiellońska Street 57/59, 03-301 Warsaw, Poland \\ ${ }^{2}$ Department of Economics and Management, University of Pisa, Via Cosimo Ridolfi 10, 56124 Pisa, Italy \\ Correspondence should be addressed to Domenico Buccella; buccella@kozminski.edu.pl
}

Received 23 July 2015; Revised 26 August 2015; Accepted 2 September 2015

Academic Editor: João Ricardo Faria

Copyright (C) 2015 D. Buccella and L. Fanti. This is an open access article distributed under the Creative Commons Attribution License, which permits unrestricted use, distribution, and reproduction in any medium, provided the original work is properly cited.

\begin{abstract}
This paper revisits the strategic selection of the bargaining agenda in a unionized industry with potential entry and decentralized negotiations for different competition modes. The incumbent chooses Right-to-Manage (RTM) or Efficient Bargaining (EB) considering two scenarios: (1) the agenda is imposed to the (potential) entrant (committed bargaining) and (2) the entrant can flexibly choose the agenda (flexible bargaining). In the mixed duopoly, the timing of the game is as follows: at stage 1, the EB firm bargains over wage and employment with its union, while the RTM firm bargains over the wage; at stage 2, the RTM firm chooses employment. This paper shows that the strategic selection of the agenda strongly depends on the interaction between the degree of market competition, the union's power, and the convergence or divergence between parties on the agenda's choice. This complex interaction leads to a very rich set of equilibrium outcomes, including multiple and even (as regards the union's preferences on the agenda) asymmetric equilibria. Compared with alternative timings in the literature, this specification leads to substantial differences with flexible bargaining: EB emerges as equilibrium in Nash strategies for a noticeably increased set of cases.
\end{abstract}

\section{Introduction}

The tight linkage between unionization and the functioning of product markets is broadly acknowledged. As Booth [1] notes, "It appears to be an empirical regularity that imperfections in the labor market are correlated with imperfections in the product market." Moreover, the presence of unionized labor markets and related bargaining institutions may constitute a potential entry barrier and, therefore, reduce the degree of competition in an industry.

These are sensitive issues for economists and policymakers as well as antitrust authorities especially when designing interventions in labor and industrial policies and regulatory economics. Using a conjectural variation $(\mathrm{CV})$ model, the aim of the present paper is to consider the impact of different competition modes on the preferences over the bargaining agenda in a monopoly with threat of entry when the strategic effects of potential competition are taken into account. In doing so, this study contributes to clarifying the effects of the interaction between alternative bargaining arrangements both in the short run (a former monopoly structure) and in the long run on the shape of the industry structure.

A few scholars have stressed that firms can use unionization as a barrier to entry in imperfectly competitive markets and exploit the bargaining scope as an entry deterrence mechanism [2, 3]. In particular, Bughin [2] studies the optimal strategic selection of the bargaining agenda (Rightto-Manage, RTM, versus Efficient Bargaining, EB, models) in labor negotiations for different market structures (duopoly versus monopoly with threat of entry). His analysis focuses on distinct constraints on the choice of the bargaining scope: (1) committed bargaining, where the incumbent's agenda is imposed on the (potential) entrant and obliged to "join the pack," and (2) flexible bargaining, in which the entrant can flexibly choose RTM or EB as its bargaining agenda.

The study of Bughin [2] is carried out considering first a given, blockaded market structure, where both firms have entered the market (oligopoly is the blockaded market structure), and then a market where the threat of entry can occur because the fixed costs can be insufficient to impede 
a potential rival from entering. Making use of a CV model, Buccella [4] revisits Bughin's [2] and derives the bargaining agendas arising as subgame perfect Nash equilibria. Buccella [4] shows that the RTM model is the equilibrium agenda whatever is the degree of competitiveness of the industry: (1) in a duopoly with blockaded entry and committed bargaining and (2) in a duopoly context with flexible bargaining both with blockaded and potential entry. However, as in Bughin [2], in the case of potential entry with committed bargaining, the incumbent may select $\mathrm{EB}$ to deter entry if the union relative bargaining power is low. Furthermore, EB as a deterrent tool is more effective the more severe the expected competition is.

As also Fanti [5] studies, those findings lie on the crucial assumption that, in the case of mixed duopoly (one firm chooses RTM, the rival EB), the timing of the game has the following specification: in the first stage, the RTM firm and its union bargain over the wage; then, in the second stage, the RTM firm chooses employment, and the EB firm negotiates with its union wage and employment. Nevertheless, as Buccella [4] underlines and Fanti [6] investigates, there is an alternative option for the timing of the game: in the first stage, the EB firm and its union bargain over wage and employment, while the RTM firm and the respective union bargain over the wage; in the second stage, the RTM firm chooses employment. This change is not innocuous. In fact, this paper shows that the strategic choice of the bargaining agenda strongly depends on the interaction between the degree of product market competition, the union's power, and the negotiating parties' convergence or divergence on the agenda's selection. This complex interplay leads to an extremely rich set of equilibrium outcomes, including multiple and even (with regard to the union's preferences on the bargaining agenda) asymmetric equilibria. Moreover, the set of cases in which the equilibrium implies the choice of EB is substantially increased. Thus, the bargaining agenda in the industry is sensitive both to the constraints on the choice of the bargaining scope and to how negotiations are conducted.

The rest of the paper is organized as follows. Section 2 develops the model and derives the results. Section 3 closes with a brief discussion.

\section{The Model and the Results}

Following Bughin [2] and Buccella [4], entry is modeled as a change in the industry market structure from a monopoly to a duopoly. As in Buccella [4], firm 1 denotes the incumbent, while firm 2 is the potential entrant. Firms produce homogeneous goods with labor unique factor of production. A constant returns-to-scale technology characterizes the industry in such a way that one unit of labor, $l$, is needed for one unit of the output, $q$. The linear (inverse) market demand is

$$
p=a-Q
$$

where $p$ denotes the price and $Q=\sum_{i} q_{i}=\sum_{i} l_{i}, i=$ 1,2 , is the total production. (The rationale for the choice of a linear demand function is twofold. First, it allows a direct comparison of the results of the current paper with the existing literature on the strategic choice of the bargaining agenda [2, 4]. Second, the use of a nonlinear demand function such as the isoelastic demand presents some technical shortcuts. The analytical derivations of the bargaining outcomes and equilibrium values in the case of monopoly are straightforward. Focusing on a simple Cournot framework (therefore, without considering the conjectural parameter), and for precise values of the demand's sensitiveness parameter, in the case of duopoly the calculations of the RTM agenda lead to analytically tractable expressions. Unfortunately, no close solutions can be obtained with regard to the EB agenda. However, under Cournot, the key result that the EB agenda can be used to deter entry still applies. The results of this exercise are available for the interested readers upon request.) Firm's profits are

$$
\begin{aligned}
& \Pi_{1}=\left(a-Q-w_{1}\right) l_{1}, \\
& \Pi_{2}=\left(a-Q-w_{2}\right) l_{2}-G
\end{aligned}
$$

for firms 1 and 2, respectively. $G$ is an exogenous fixed cost for the potential entrant. The model assumes that the firms decide their production levels according to a CV model (see [7]). Thus define $\phi \in(-1,1)$ as $\phi=d q_{j}\left(q_{i}\right) / d q_{i}$ : if $\phi=0$, the model collapses in the Cournot model; for $\phi>0$, the firms act in a more collusive way, whereas for $\phi<0$ the industry is more competitive. The incumbent and the (potential) entrant are both unionized. Unions maximize the following objective function:

$$
\Omega_{i}=w_{i} l_{i}
$$

The bargaining structure in the industry is at the firm level. The bargaining solution is modeled by the following generalized Nash Product:

$$
\mathrm{NP}=\left(\Omega_{i}\right)^{\alpha}\left(\Pi_{i}\right)^{1-\alpha},
$$

where the parameter $\alpha \in(0,1)$ measures the parties' relative strength which is assumed to be identical across bargaining units. The game is solved by backward induction to derive the subgame perfect Nash equilibria. As in Bughin [2] and Buccella [4], the sequence of moves is the following. First, the incumbent selects its bargaining agenda; then, the potential entrant, given the available options, decides whether to enter in the industry. Finally, the wage and employment levels are simultaneously negotiated in the case of EB; or wages are negotiated before the output decisions in the case of RTM. With respect to the mixed duopoly, suppose that firm 1 negotiates under the EB, whereas firm 2 negotiates under the RTM. However, differently from Bughin [2], Buccella [4], and Fanti [5], and similarly to Fanti [6], the timing of the game is as follows.

In stage 1 , firm 1 and union 1 bargain over the wage and employment levels, whereas firm 2 and union 2 bargain over the wage. In stage 2 , firm 2 chooses employment.

Using (2)-(4) and solving the Nash Product in (5), direct computations allow obtaining the expressions in Table 1, which reports also the corresponding results of Buccella [4]. The Appendix provides the extensive derivations. 


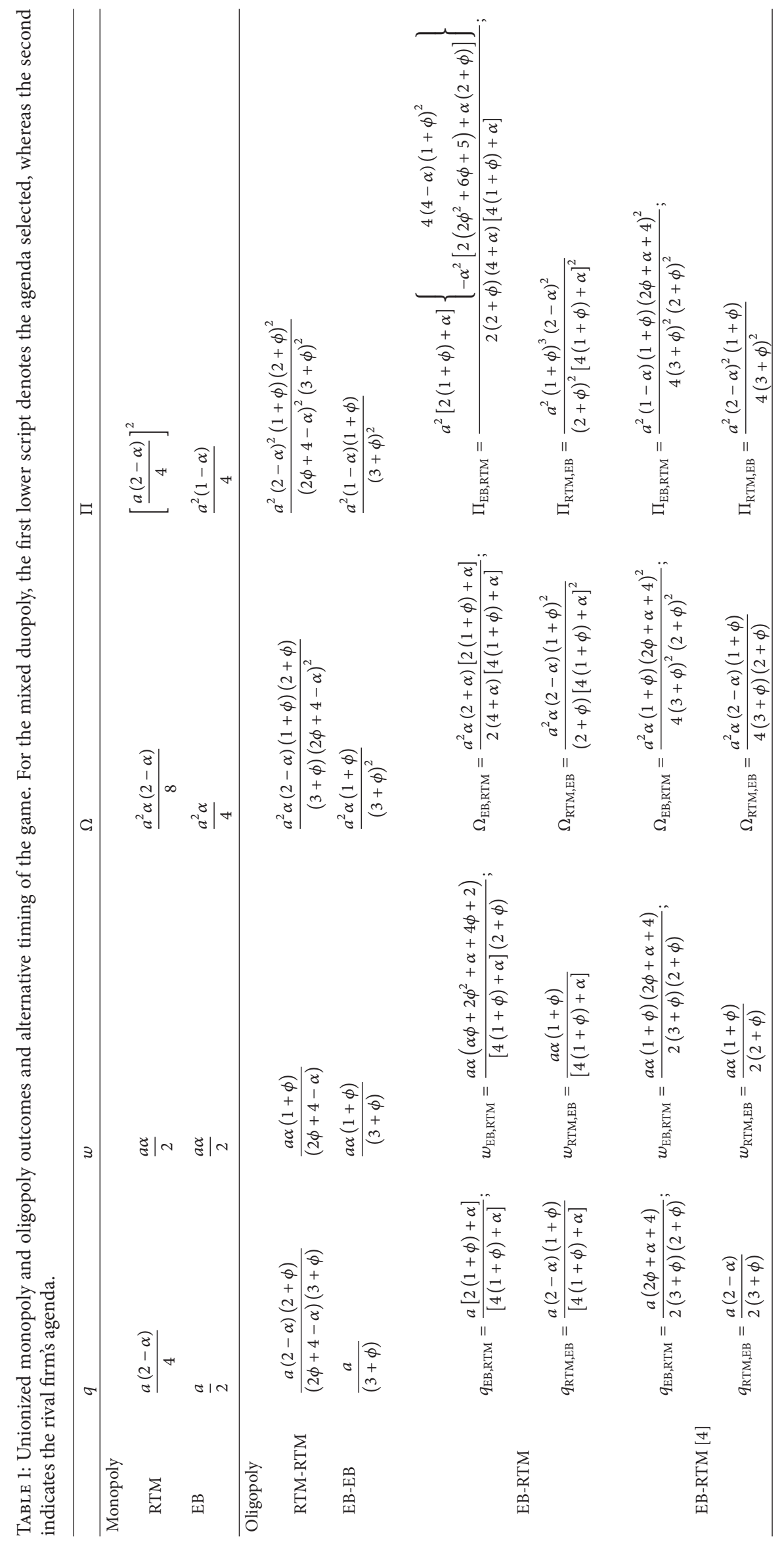


A preliminary observation is required. In the case of committed bargaining, the results of Buccella [4] also hold under the new timing of the game. It is now possible to focus on the flexible bargaining. First, let us consider the blockaded entry. To select its bargaining agenda, the incumbent firm evaluates the profits associated with every regime and takes into account the entrant's strategic choice. A preliminary analytical inspection reveals the following result. The nonnegativity condition on profits implies that $\Pi_{i} \geq 0$. However, in the case of mixed duopoly, it occurs that

$$
\begin{aligned}
& \Pi_{i}^{\mathrm{EB}, \mathrm{RTM}}>0 \Longrightarrow \phi^{T}(\alpha) \\
& \quad>\frac{\alpha^{3}+12 \alpha^{2}+8 \alpha-32+\sqrt{\alpha^{6}-8 \alpha^{5}-32 \alpha^{4}+32 \alpha^{3}+128 \alpha^{2}}}{8\left(4-\alpha-\alpha^{2}\right)},
\end{aligned}
$$

while $\Pi_{i}^{\mathrm{EB}, \mathrm{RTM}} \leq 0 \Rightarrow \phi \leq \phi^{T}(\alpha)$. The solid line in Figure 1 graphically represents this condition. The intersections between all the firms' duopoly outcomes in Table 1 and the condition in (6) generate eight regions in the relevant $(\alpha, \phi)$-space, as Figure 1 depicts. In the regions I-VIII of $(\alpha, \phi)$-space, the following inequalities between duopoly profits hold:

Region I: $\Pi_{i}^{\mathrm{EB}, \mathrm{RTM}}>\Pi_{i}^{\mathrm{RTM}, \mathrm{RTM}}>\Pi_{i}^{\mathrm{EB}, \mathrm{EB}}>\Pi_{i}^{\mathrm{RTM}, \mathrm{EB}}$, $i=1,2$. The $\mathrm{EB}$ agenda is the dominant strategy for firms. EB is the equilibrium agenda.

Region II: $\Pi_{i}^{\mathrm{RTM}, \mathrm{RTM}}>\Pi_{i}^{\mathrm{EB}, \mathrm{RTM}}>\Pi_{i}^{\mathrm{RTM}, \mathrm{EB}}>\Pi_{i}^{\mathrm{EB}, \mathrm{EB}}$, $i=1,2$. The RTM agenda is the dominant strategy for firms. RTM is the equilibrium agenda.

Region III: it is the same as Region II. Therefore, RTM is the dominant strategy for firms. RTM is the equilibrium agenda.

Region IV: $\Pi_{i}^{\mathrm{RTM}, \mathrm{RTM}}>\Pi_{i}^{\mathrm{RTM}, \mathrm{EB}}>\Pi_{i}^{\mathrm{EB}, \mathrm{EB}}>\Pi_{i}^{\mathrm{EB}, \mathrm{RTM}}$, $i=1,2$. RTM agenda is the dominant strategy and therefore is equilibrium agenda.

Region $\mathrm{V}: \Pi_{i}^{\mathrm{RTM}, \mathrm{RTM}}>\Pi_{i}^{\mathrm{EB}, \mathrm{RTM}}>\Pi_{i}^{\mathrm{EB}, \mathrm{EB}}>\Pi_{i}^{\mathrm{RTM}, \mathrm{EB}}$, $i=1$, 2. In this case, both RTM and EB agendas arise as Nash Equilibrium.

Region VI: $\Pi_{i}^{\mathrm{RTM}, \mathrm{RTM}}>\Pi_{i}^{\mathrm{EB}, \mathrm{RTM}}>\Pi_{i}^{\mathrm{EB}, \mathrm{EB}}>$ $\Pi_{i}^{\mathrm{RTM}, \mathrm{EB}}, i=1,2$. In this case, both RTM and $\mathrm{EB}$ agendas arise as Nash Equilibrium.

Region VII: $\Pi_{i}^{\mathrm{RTM}, \mathrm{RTM}}>\Pi_{i}^{\mathrm{EB}, \mathrm{EB}}>\Pi_{i}^{\mathrm{RTM}, \mathrm{EB}}>$ $\Pi_{i}^{\mathrm{EB}, \mathrm{RTM}}, i=1$, 2. In this case, both RTM and EB agendas arise as Nash Equilibrium.

Region VIII: $\Pi_{i}^{\mathrm{RTM}, \mathrm{RTM}}>\Pi_{i}^{\mathrm{RTM}, \mathrm{EB}}>\Pi_{i}^{\mathrm{EB}, \mathrm{EB}}>$ $\Pi_{i}^{\mathrm{EB}, \mathrm{RTM}}, i=1,2$. Given this payoff structure, RTM is the Nash Equilibrium.

Figure 2 summarizes these findings. In the mixed duopoly, unless the degree of competition is highly intensive, that is, $\phi \leq \phi^{C}(\alpha)=(\sqrt{2} \sqrt{\alpha}-2-\alpha) / 2$, the firm that selects $\mathrm{EB}$ pays a wage lower than the game with the timing proposed by Buccella [4] (see Table 1 above), expands output, and thus improves margins and profits. The reason for this result is that the incumbent takes into account the entrant's bestreply function when bargaining over wage and employment

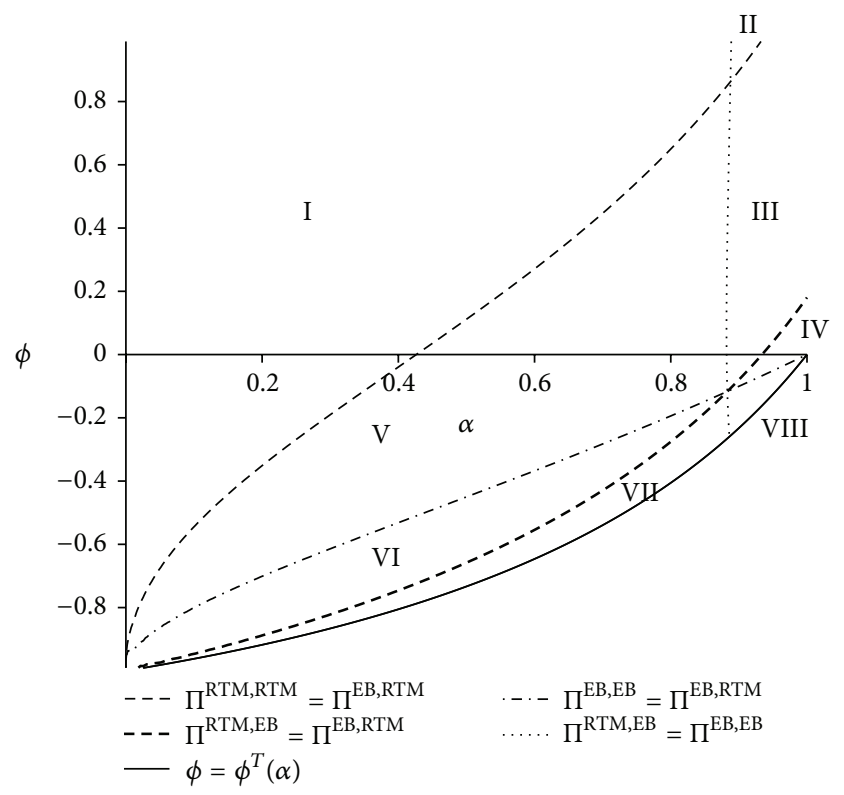

FIGURE 1: Duopoly profits in $(\alpha, \phi)$-space. The demand parameter $a$ scales up/down the relevant expressions while keeping the qualitative findings unaltered.

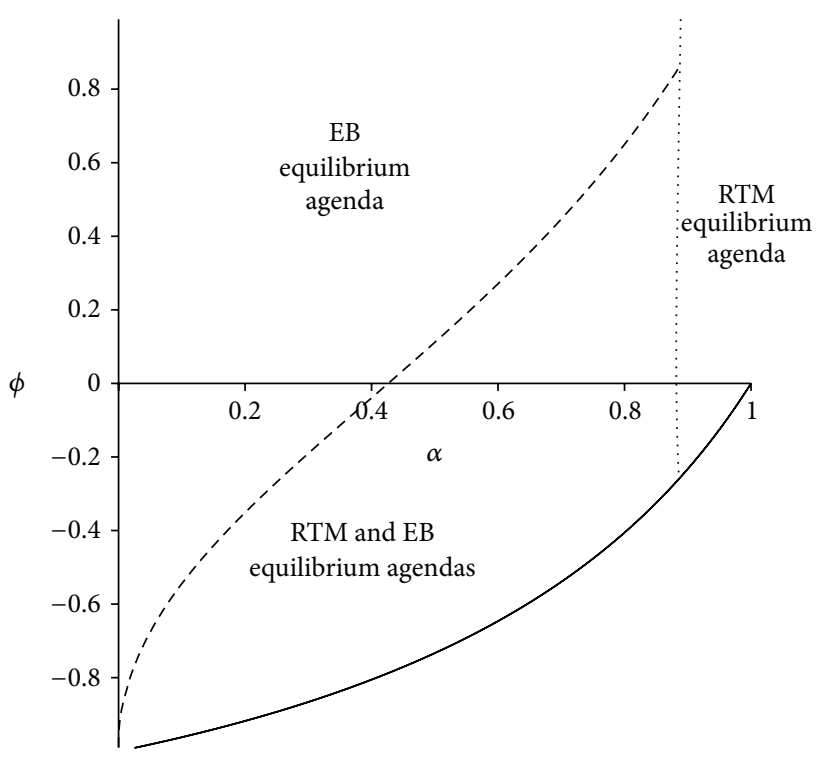

FIGURE 2: Firms' equilibrium agendas. The demand parameter $a$ scales up/down the relevant expressions while keeping the qualitative findings unaltered.

with the union. As a consequence, the incumbent evaluates that the entrant reduces the output level after the wage negotiations as a response to an increase in production. This reasoning is reinforced when the entrant is expected to act in a less competitive way. In other words, the incumbent behaves as a Stackelberg quantity leader, having the firstmover advantage.

In region I, EB is the firms' dominant strategy: the entrant selects EB regardless of the incumbent's move. Thus, 


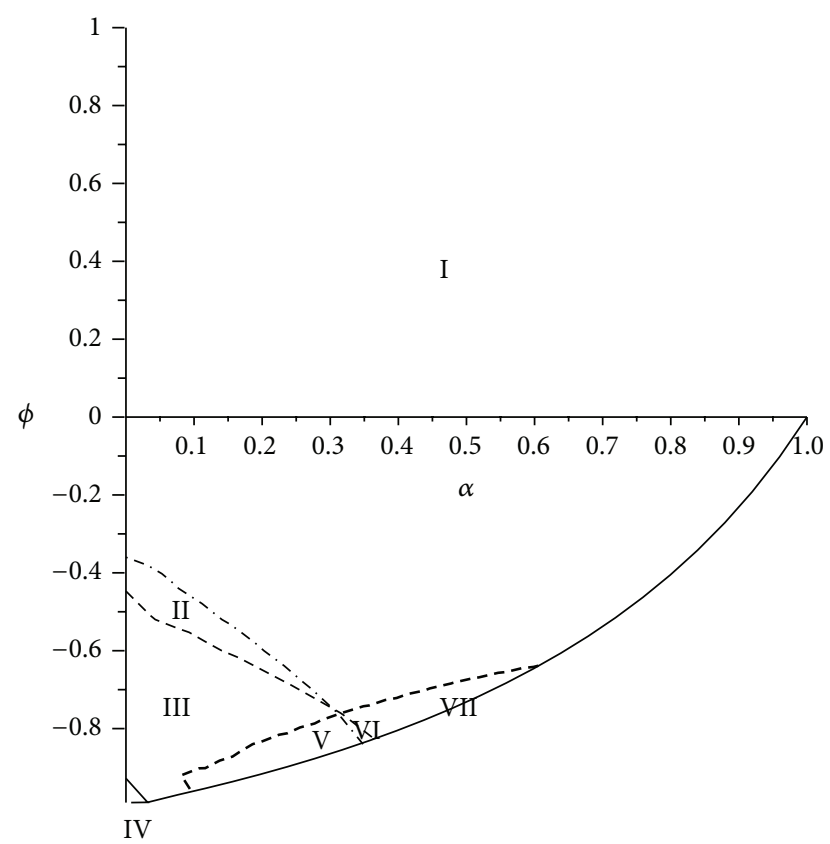

FIgURE 3: Union utilities in $(\alpha, \phi)$-space. The demand parameter $a$ scales up/down the relevant expressions while keeping the qualitative findings unaltered.

the adoption of the EB agenda is the industry equilibrium. Noteworthy, $\Pi_{i}^{\mathrm{RTM}, \mathrm{RTM}}>\Pi_{i}^{\mathrm{EB}, \mathrm{EB}}$ : both firms would be better off by introducing RTM. In other words, the firms are cast into a classical Prisoner's Dilemma. The previous finding can be summarized in Proposition 1.

Proposition 1. Under flexible bargaining with blockaded entry and firms deciding the agenda, one has the following: (1) the selection of the EB agenda is the dominant strategy for the firms for a combination of sufficiently low bargaining power of the unions and a certain degree of collusive behavior and in presence of intense market competition with unions extremely weak; however, firms face Prisoner's Dilemma situation; (2) multiple symmetric equilibria emerge in equilibrium for intermediate values of the unions' bargaining power and restricted market competition and for a wide set of the unions' bargaining power when markets are competitive; and (3) RTM is the equilibrium agenda for every degree of industry competition, provided that the unions' bargaining power is adequately high. The threat of market entry under flexible bargaining strengthens the strategic move arguments for the incumbent.

Let us now consider the unions' viewpoint. Considering the restriction in (6), the intersections between all the unions' utility payoffs in Table 1 generate seven regions in the relevant $(\alpha, \phi)$-plane, as Figure 3 depicts. In the regions I-VII of $(\alpha, \phi)$-space, the following inequalities between the unions' utility hold:

Region I: $\Omega_{i}^{\mathrm{EB}, \mathrm{RTM}}>\Omega_{i}^{\mathrm{EB}, \mathrm{EB}}>\Omega_{i}^{\mathrm{RTM}, \mathrm{RTM}}>\Omega_{i}^{\mathrm{RTM}, \mathrm{EB}}$, $i=1,2$. The EB agenda is the dominant strategy for unions. EB is the unions' preferred agenda.
Region II: $\Omega_{i}^{\mathrm{EB}, \mathrm{RTM}}>\Omega_{i}^{\mathrm{EB}, \mathrm{EB}}>\Omega_{i}^{\mathrm{RTM}, \mathrm{EB}}>\Omega_{i}^{\mathrm{RTM}, \mathrm{RTM}}$, $i=1,2$. The EB agenda is the dominant strategy for unions. EB is the unions' preferred agenda.

Region III: $\Omega_{i}^{\mathrm{EB}, \mathrm{RTM}}>\Omega_{i}^{\mathrm{RTM}, \mathrm{EB}}>\Omega_{i}^{\mathrm{EB}, \mathrm{EB}}>$ $\Omega_{i}^{\mathrm{RTM}, \mathrm{RTM}}, i=1,2$. In this case, two asymmetric Nash Equilibria arise: one union prefers EB and the other RTM.

Region IV: $\Omega_{i}^{\mathrm{EB}, \mathrm{RTM}}>\Omega_{i}^{\mathrm{RTM}, \mathrm{EB}}>\Omega_{i}^{\mathrm{RTM}, \mathrm{RTM}}>$ $\Omega_{i}^{\mathrm{EB}, \mathrm{EB}}, i=1,2$. In this case, two asymmetric Nash Equilibria arise: one union prefers EB and the other RTM.

Region V: $\Omega_{i}^{\mathrm{EB}, \mathrm{RTM}}>\Omega_{i}^{\mathrm{RTM}, \mathrm{EB}}>\Omega_{i}^{\mathrm{RTM}, \mathrm{RTM}}>\Omega_{i}^{\mathrm{EB}, \mathrm{EB}}$, $i=1,2$. In this case also two asymmetric Nash Equilibria arise: one union prefers EB and the other RTM.

Region VI: $\Omega_{i}^{\mathrm{EB}, \mathrm{RTM}}>\Omega_{i}^{\mathrm{RTM}, \mathrm{RTM}}>\Omega_{i}^{\mathrm{RTM}, \mathrm{EB}}>$ $\Omega_{i}^{\mathrm{EB}, \mathrm{EB}}, i=1,2$. As region III and region IV, two asymmetric Nash Equilibria arise: one union prefers EB and the other RTM.

Region VII: $\Omega_{i}^{\mathrm{EB}, \mathrm{RTM}}>\Omega_{i}^{\mathrm{RTM}, \mathrm{RTM}}>\Omega_{i}^{\mathrm{EB}, \mathrm{EB}}>$ $\Omega_{i}^{\mathrm{RTM}, \mathrm{EB}}, i=1,2$. The EB agenda is the dominant strategy for unions and, therefore, is the unions' preferred agenda.

Figure 4 sums up these findings. It is immediately evident that, from the unions' standpoint, the EB agenda is predominantly the preferred agenda. However, when the intensity of market competition increases (negative values of $\phi$ ), areas with multiple asymmetric equilibria emerge. In other words, unions may face a situation with the characteristics of an anticoordination game. A possible explanation could be as follows. The RTM agenda leads to a higher wage rate but causes a lower employment level, while the EB agenda does the opposite. However, for the combinations of the parameters in regions III, IV, and V, the unions reciprocally benefit from that trade-off only if the firms negotiate with different agendas: the output expansion, and therefore employment gains for the EB firm more than compensate the lower wage level; the high intensive competition level ensures that, in spite of the low bargaining power, the wage gains overcome the employment losses with the RTM agenda.

This result is in contrast to Dobson [8] who finds that, with Bertrand competition and close substitute products, unions would unambiguously agree on the RTM agenda. The plausible rationale for this discrepancy may reside in a different timing considered in the mixed oligopoly when one firm adopts the "participatory framework." (The analysis conducted by Dobson [8] considers that negotiations are conducted on the basis of the "participatory framework" [9] where the firms and unionized labor bargain simultaneously over wages and price schedules which are, in that context, the variables at the parties' discretion.)

A straightforward comparison of Figures 2 and 4 shows that an extensive area exists in the relevant parameter space where the bargaining parties have a common interest in introducing the EB agenda during the negotiations. Figure 5 


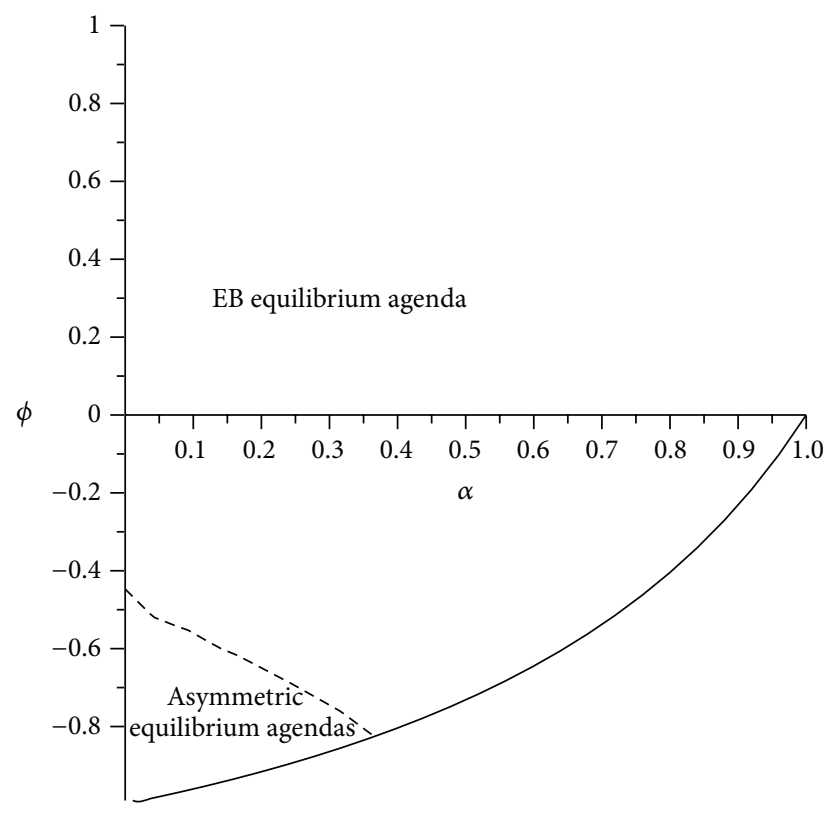

FIGURE 4: Unions' equilibrium agendas. The demand parameter $a$ scales up/down the relevant expressions while keeping the qualitative findings unaltered.

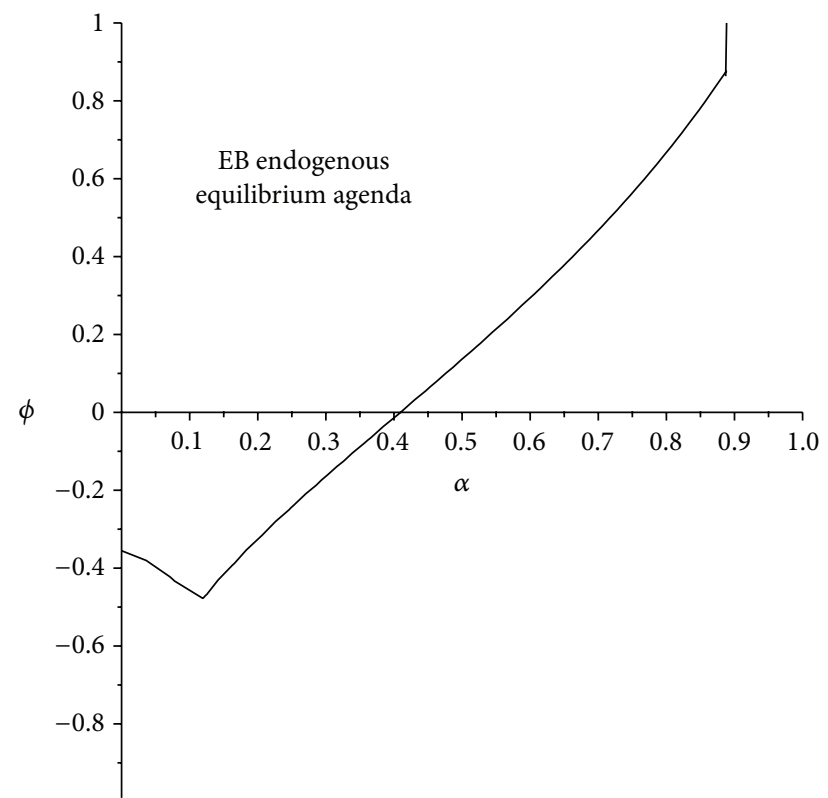

FIGURE 5: Endogenous equilibrium agenda. The demand parameter $a$ scales up/down the relevant expressions while keeping the qualitative findings unaltered.

depicts this area. It is evident that the EB agenda endogenously emerges when the industry is slightly competitive or tends to restrict competition remarkably when the unions' relative bargaining power is low.

With respect to flexible bargaining with threat of entry, the rationale for the entrant and incumbent's strategic moves described above is reinforced. Proposition 2 summarizes these results.
Proposition 2. Under flexible bargaining with blockaded entry and endogenous selection of the bargaining agenda $E B$ emerges in equilibrium in the presence of slight or restricted market competition when the unions' relative bargaining power is low and for a combination of high-intermediate values of the union bargaining power and less competitive markets. The threat of market entry under flexible bargaining strengthens the strategic move arguments for the incumbent.

\section{Conclusion}

In a unionized duopoly with potential entry, this paper considers the following scenario: in the first stage of the game, the incumbent negotiates over the wage and employment levels, whereas the entrant bargains over the wage; then, in the second stage, the entrant selects the employment level. The key results are as follows. Under flexible bargaining, the $\mathrm{EB}$ is the dominant strategy for the firms for a combination of relatively low unions' bargaining power and a certain degree of collusive behavior and in presence of competitive markets when the unions are weak; therefore, EB negotiations in all the bargaining units arise as the industry equilibrium.

However, firms are cast into Prisoner's Dilemma game. For the other relevant set of the model's parameters, the following results hold. First, multiple symmetric equilibria emerge in equilibrium (1) for intermediate values of the unions' bargaining power and with restricted market competition and (2) for a wide set of the unions' bargaining power and markets with an intense competition degree. Second, RTM is the industry equilibrium agenda for every degree of industry competition, provided that the unions' bargaining power is adequately high.

Taking into consideration the unions' preferences toward the bargaining agenda, it is found that unions and firms endogenously select the EB agenda when the unions' relative bargaining power is low in the presence of slight or restricted market competition and for high-intermediate values of the union bargaining power in the presence of markets with restricted competition.

These findings complement Buccella's [4] result where, under flexible bargaining with an alternative timing in mixed duopoly, universal RTM is always the industry equilibrium agenda. In other words, in the case of flexible bargaining, the timing proposed here leads to substantial differences in results: the set of cases in which the equilibrium implies the choice of EB is increased. The timing of the game plays a crucial role in determining the equilibrium bargaining agenda in a unionized oligopoly. Therefore, these results may provide useful insights for antitrust authorities and policy makers wishing to intervene in labor regulations in most of the observed and realistic cases where the unions' power is not too high.

\section{Appendix}

\section{Mixed Duopoly Outcomes in Table 1}

This Appendix derives the equilibrium outcomes under mixed duopoly. Assume that firm 1, the incumbent, bargains 
with its union under EB, while firm 2, the entrant, negotiates with its union under RTM. From (3), the first-order condition for firm 2 determines the best-reply function:

$$
\frac{\partial \Pi_{2}}{\partial q_{2}}=0 \Longrightarrow q_{2}=\frac{\left(a-q_{1}-w_{2}\right)}{(2+\phi)} \text {. }
$$

Therefore, using (1), (2), and (4), the maximization problem in (5) for the incumbent is

$$
\begin{aligned}
& \max \mathrm{NP}_{1}\left(w_{1}, q_{1}\right)=\left(w_{1} q_{1}\right)^{\alpha} \\
& \cdot\left\{\left[a-q_{1}-\left(\frac{a-q_{1}-w_{2}}{2+\phi}\right)-w_{1}\right] q_{1}\right\}^{1-\alpha} .
\end{aligned}
$$

First-order conditions yield the following expressions:

$$
\begin{aligned}
& w_{1}=\frac{\alpha\left[(1+\phi)\left(a-q_{1}\right)+w_{2}\right]}{2+\phi} \quad \\
& \quad \text { (rent sharing curve) } \\
& w_{1}=\frac{a(1+\phi)+(1+\phi)(\alpha-2) q_{1}+w_{2}}{2+\phi}
\end{aligned}
$$

(contract curve).

On the other hand, the entrant also takes into consideration its optimal output response in the successive stage of the game. Therefore, the entrant's bargaining problem under RTM is to set $w_{2}$ to maximize

$$
\begin{aligned}
\max \mathrm{NP}_{2}\left(w_{2}\right)= & {\left[\frac{w_{2}\left(a-q_{1}-w_{2}\right)}{2(1+\phi)}\right]^{\alpha} } \\
& \cdot\left[\frac{\left(a-q_{1}-w_{2}\right)^{2}(1+\phi)}{(2+\phi)^{2}}\right]^{1-\alpha} .
\end{aligned}
$$

The first-order condition leads to

$$
w_{2}=\frac{a \alpha\left(1-q_{1}\right)}{2} .
$$

Substituting back (A.5) into (A.3) and solving for $w_{1}$ and $q_{1}$, we obtain

$$
\begin{aligned}
& w_{1}=\frac{a \alpha\left(\alpha \phi+2 \phi^{2}+\alpha+4 \phi+2\right)}{[4(1+\phi)+\alpha](2+\phi)}, \\
& q_{1}=\frac{a[2(1+\phi)+\alpha]}{[4(1+\phi)+\alpha]},
\end{aligned}
$$

the incumbent's equilibrium wage and output under EB ( $w_{\mathrm{EB}, \mathrm{RTM}}$ and $q_{\mathrm{EB}, \mathrm{RTM}}$ in Table 1 , fourth row). Replacing (A.7) into (A.5), the entrant's equilibrium wage under RTM $\left(w_{\mathrm{RTM}, \mathrm{EB}}\right.$ in Table 1 , fourth row $)$ is

$$
w_{2}=\frac{a \alpha(1+\phi)}{[4(1+\phi)+\alpha]} \text {. }
$$

Finally, substitution of (A.7) and (A.8) into (A.1) leads to the entrant's output level in equilibrium $\left(q_{\mathrm{RTM}, \mathrm{EB}}\right.$ in Table 1 , fourth row):

$$
q_{2}=\frac{a(2-\alpha)(1+\phi)}{[4(1+\phi)+\alpha](2+\phi)} .
$$

Direct substitutions of (A.6)-(A.9) into (2)-(4) in the main text allow deriving all the other expressions in Table 1.

\section{Conflict of Interests}

The authors declare that there is no conflict of interests regarding the publication of this paper.

\section{Acknowledgment}

The authors would like to thank an anonymous referee for useful comments.

\section{References}

[1] A. L. Booth, The Economics of the Trade Union, Cambridge University Press, Cambridge, Mass, USA, 1995.

[2] J. Bughin, "The strategic choice of union-oligopoly bargaining agenda," International Journal of Industrial Organization, vol. 17, no. 7, pp. 1029-1040, 1999.

[3] S. Vannini and J. Bughin, "To be (unionized) or not to be? A case for cost-raising strategies under Cournot oligopoly," European Economic Review, vol. 44, no. 9, pp. 1763-1781, 2000.

[4] D. Buccella, "Corrigendum to 'the strategic choice of unionoligopoly bargaining agenda [International Journal of Industrial Organization 17, 1029-40.],' International Journal of Industrial Organization, vol. 29, no. 6, pp. 690-693, 2011.

[5] L. Fanti, "When do firms and unions agree on a monopoly union or an efficient bargaining arrangement?" Discussion Paper 181, Department of Economics and Management, University of Pisa, 2014.

[6] L. Fanti, "Union-firm bargaining agenda: right-to-manage or efficient bargaining?” Economics Bulletin, vol. 35, no. 2, pp. 936948, 2015.

[7] G. De Fraja, "Staggered vs. synchronised wage setting in oligopoly," European Economic Review, vol. 37, no. 8, pp. 1507$1522,1993$.

[8] P. W. Dobson, "Union-firm interaction and the right to manage," Bulletin of Economic Research, vol. 49, no. 3, pp. 213-229, 1997.

[9] J. Svejnar, "On the theory of a participatory firm," Journal of Economic Theory, vol. 27, no. 2, pp. 313-330, 1982. 

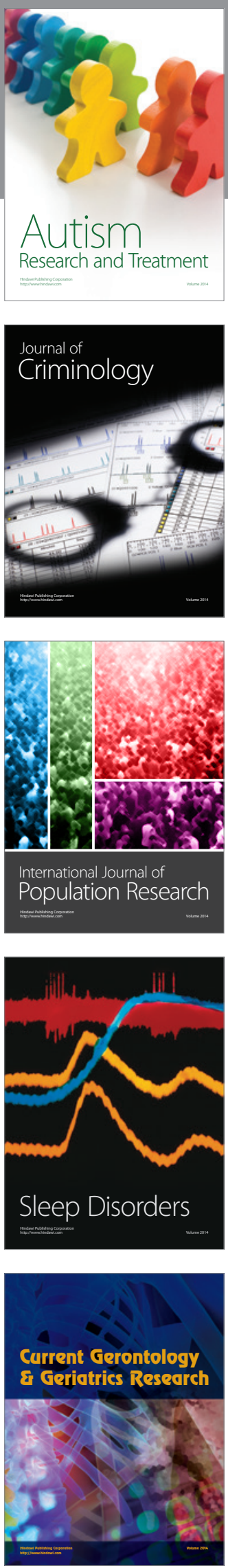
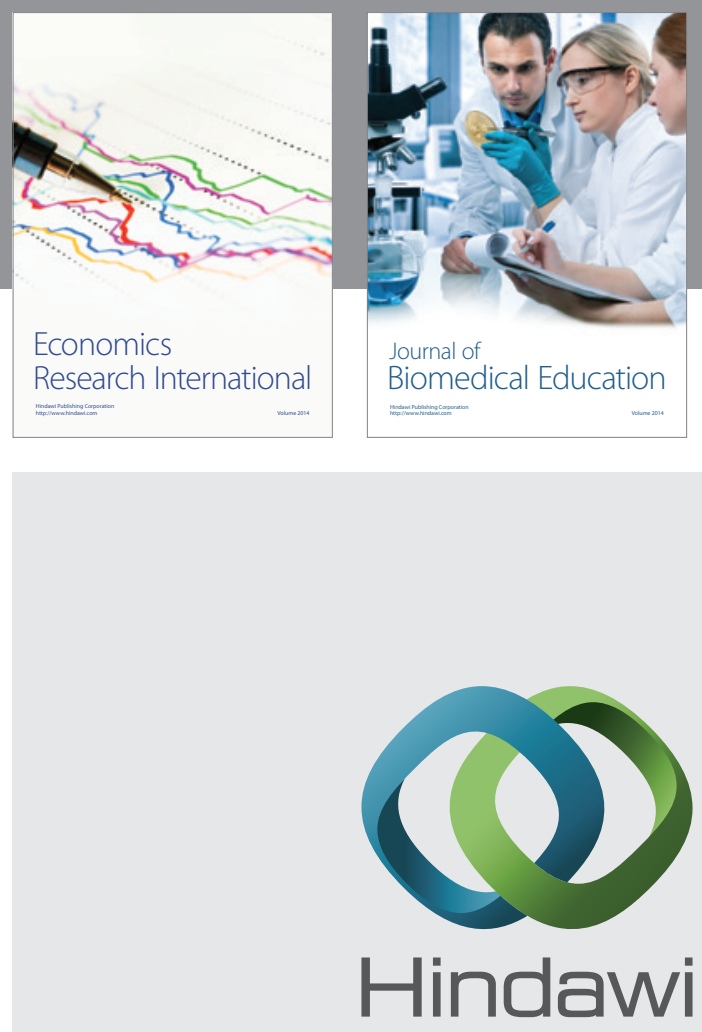

Submit your manuscripts at

http://www.hindawi.com
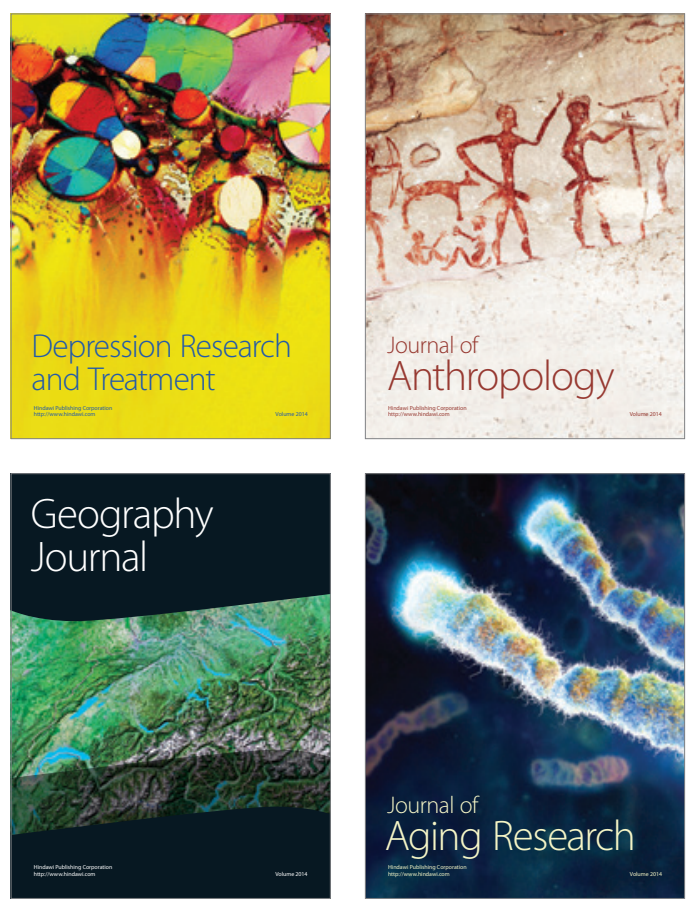
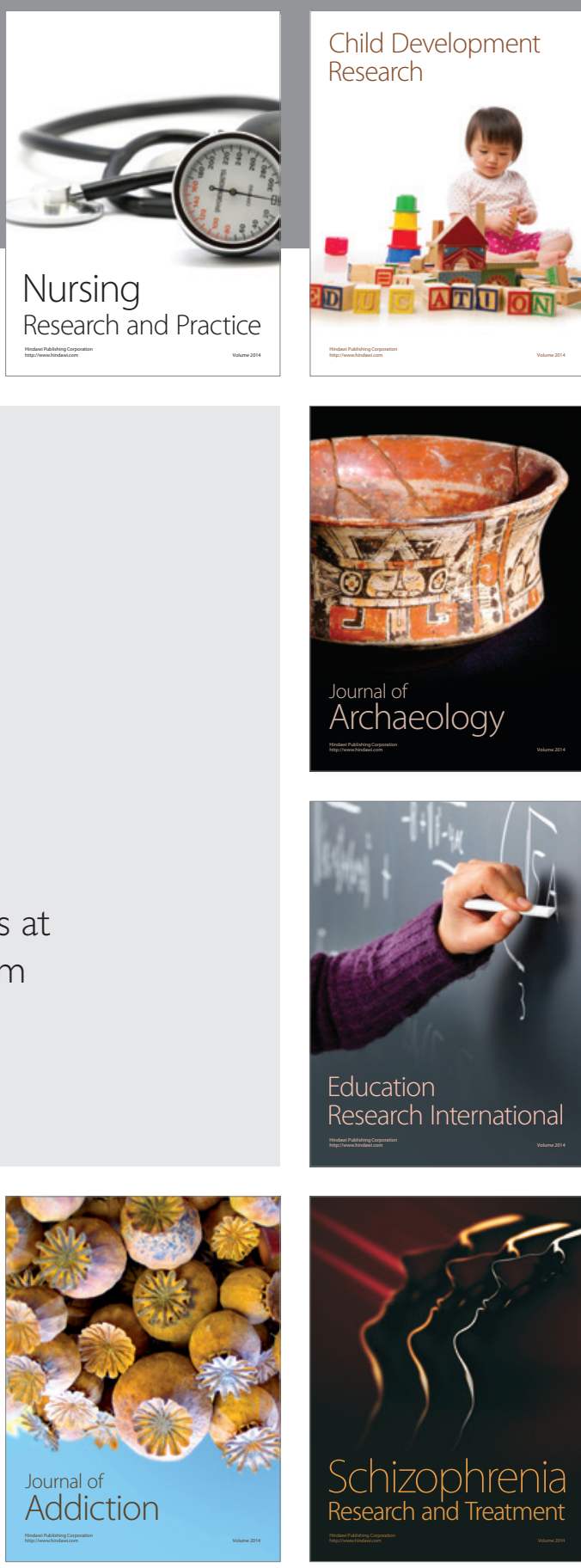

(D)
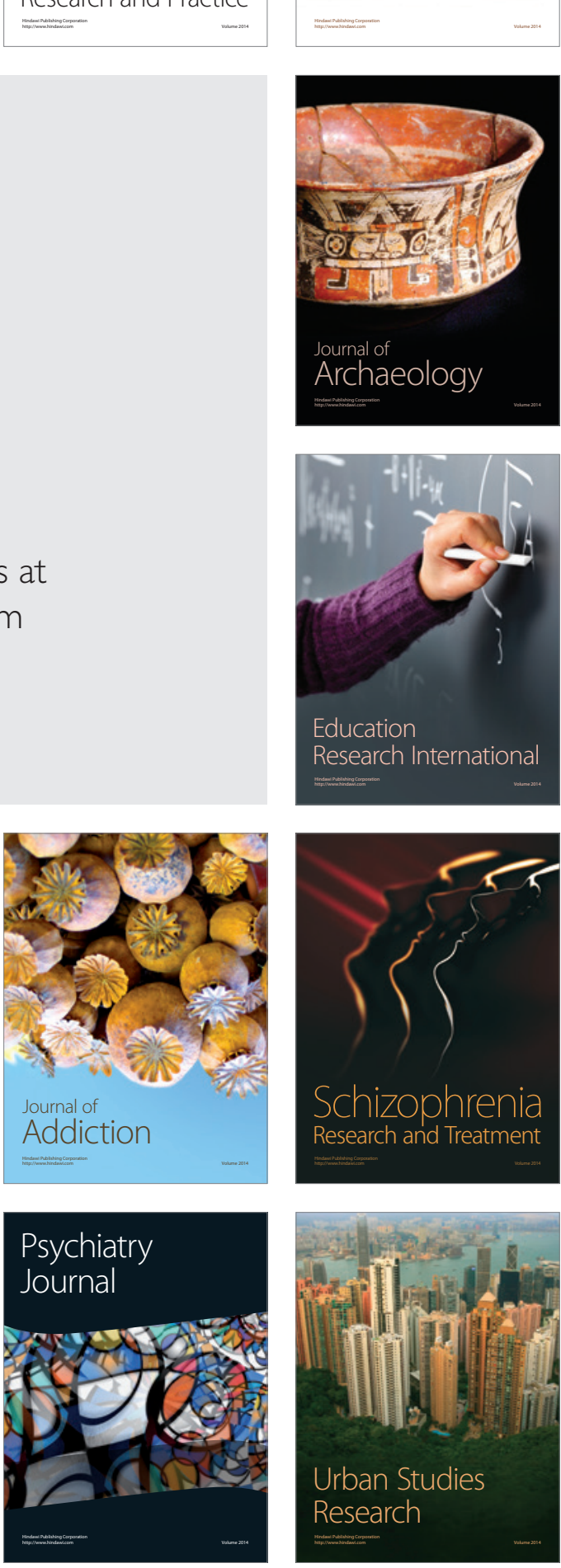